\title{
Catalytic Reductive Degradation of Methyl Orange Using Air Resilient Copper Nanostructures
}

\author{
Razium Ali Soomro, ${ }^{1,2}$ Ayman Nafady, ${ }^{3,4}$ Sirajuddin, ${ }^{1}$ Syed Tufail Hussain Sherazi, ${ }^{1}$ \\ Nazar Hussain Kalwar, ${ }^{1,2}$ Mohammad Raza Shah, ${ }^{5}$ and Keith Richard Hallam ${ }^{2}$ \\ ${ }^{1}$ National Centre of Excellence in Analytical Chemistry, University of Sindh, Jamshoro 76080, Pakistan \\ ${ }^{2}$ Interface Analysis Centre, School of Physics, University of Bristol, Bristol BS8 1TL, UK \\ ${ }^{3}$ Department of Chemistry, College of Science, King Saud University, Riyadh 11451, Saudi Arabia \\ ${ }^{4}$ Chemistry Department, Faculty of Science, Sohag University, Sohag 82524, Egypt \\ ${ }^{5}$ International Centre for Chemical and Biological Sciences, H.E.J. Research Institute of Chemistry University of Karachi, \\ Karachi 75500, Pakistan \\ Correspondence should be addressed to Nazar Hussain Kalwar; nazarkalwar@gmail.com
}

Received 16 November 2014; Revised 26 December 2014; Accepted 27 December 2014

Academic Editor: Xingcai Wu

Copyright (C) 2015 Razium Ali Soomro et al. This is an open access article distributed under the Creative Commons Attribution License, which permits unrestricted use, distribution, and reproduction in any medium, provided the original work is properly cited.

The study describes the application of oxidation resistant copper nanostructures as an efficient heterogeneous catalyst for the treatment of organic dye containing waste waters. Copper nanostructures were synthesized in an aqueous environment using modified surfactant assisted chemical reduction route. The synthesized nanostructures have been characterized by UV-Vis, Fourier transform infrared spectroscopy FTIR spectroscopy, Atomic force microscopy (AFM), Scanning Electron Microscopy (SEM), and X-ray diffractometry (XRD). These surfactant capped $\mathrm{Cu}$ nanostructures have been used as a heterogeneous catalyst for the comparative reductive degradation of methyl orange $(\mathrm{MO})$ in the presence of sodium borohydride $\left(\mathrm{NaBH}_{4}\right)$ used as a potential reductant. Copper nanoparticles ( $\mathrm{Cu} \mathrm{NPs}$ ) were found to be more efficient compared to copper nanorods (Cu NRds) with the degradation reaction obeying pseudofirst order reaction kinetics. Shape dependent catalytic efficiency was further evaluated from activation energy $\left(E_{A}\right)$ of reductive degradation reaction. The more efficient $\mathrm{Cu}$ NPs were further employed for reductive degradation of real waste water samples containing dyes collected from the drain of different local textile industries situated in Hyderabad region, Pakistan.

\section{Introduction}

Major scientific interest targeting fabrication of metal nanostructures of distinct shape and diminutive size has been developed in recent years because of their exclusive properties as compared to their bulk counter parts [1-3]. The capability to fashion metal nanostructures with variety of shapes and sizes allows for exploring their fascinating applications in fields like catalysis, electronics, sensors, optical devices, and so on. Most of the unique properties shown by metal nanostructures are a consequence of their nanosize scale regime. However, recently, it has been found that properties of nanomaterials are also influenced by their shape; for example, Jana and Murphy (2002) [4] reported shape dependent surface plasmon resonance (SPR) peaks of silver and gold nanoparticles. Similarly, anisotropic behavior in optical properties of copper nanorods has also been reported by Henglein (1989) [5]. Thus, special shaped nanocomposite materials are the focus of present day scientific research. From the present literature perspective, development of a feasible synthesis method for such nanomaterials is an important task. Among all the methods employed today (radiation method [6], microemulsion method [7], thermal decomposition method [8], laser ablation method [9], and aqueous chemical reduction method [10]), the aqueous reduction route is the most preferred for its simple and economic strategy with high yield and quality of the desired product and ease of control over particle size and distribution with 
various experimental parameters [11-14]. Although a variety of metal nanostructures are being employed for numerous applications in various fields, the use of nanosize metal structures as a heterogeneous recyclable catalyst in different environmental problems associated with hazardous wastes and toxic water pollutants pollution is the need of the day.

The textile industry and its waste water have been increasing proportionally, making it one of the main sources of severe water pollution worldwide [15]. In particular, dyes comprise a major section of industrial waste water effluents as they are released in abundance; up to $50 \%$ of dyes may be lost directly into waterways due to inefficient and uneconomic dyeing techniques. The release of such chemicals in aquatic systems is of environmental concern due to their carcinogenic, persistent, and recalcitrant nature [16]. Dyes released in waste water may also undergo incomplete anaerobic degradation, inducing additional toxicity caused by mutagenic end products. Besides this, coloring decreases sunlight penetration and oxygen dissolution in water which is also a considerable threat to the aquatic ecosystem [17]. In order to cope with increasingly strict legislations and regulations concerning waste water management, the associated industries are required to find green, efficient, and economically viable waste water treatment methods. Water treatment methods include adsorption, biological, coagulation routes, and ozonation [18]. However, these methods are time-consuming, expensive, and inefficient and result in secondary pollution with overall increase in the method cost because of the extra disposal procedures. Advanced oxidation processes (AOPs), employing metal oxides such as $\mathrm{TiO}_{2}$ and $\mathrm{ZnO}$, are technically feasible degradation processes, but the requirement for short wavelength light sources and low quantum yields restrain their widespread acceptance as efficient and practical remediation processes [19-22]. Recently, multistep processes for significant advancement in practical applications regarding dye degradation have been reported [23]. Among such processes, reductive degradation of organic dyes with metal nanostructures is a convenient degradation model system which is not only viable in terms of efficiency and costliness but also greener as it provides biodegradable end products like aromatic amines, which are readily and easily degraded by microorganisms [24]. Hassan et al. (2011) [25] reported the catalytic reduction of mixture of dyes, using gold nanoparticles within $15 \mathrm{~s}$ of reaction time. Similarly, Xu et al. (2008) [26] used Pd nanoparticles with good catalytic properties in the degradation of azo dyes. Nafady et al. (2011) [27] reported reductive degradation of methylene blue with cysteine capped gold nanoparticles in just $5 \mathrm{~min}$ of reaction time. Ai and Jiang (2013) [28] used alginate hydrogel (AH) capped silver nanoparticles for the heterogeneous catalytic reduction of 4-nitrophenol by $\mathrm{NaBH}_{4}$ in aqueous solution and Sau et al. (2001) [29] addressed catalysis of eosin reduction in the presence of $\mathrm{NaBH}_{4}$ with Triton X-100 coated gold nanoparticles. From all the previous reports, it is clear that most of the relevant recent studies carried out in the field of catalysis have focused on the use of transition metals like silver, gold, and platinum with less understanding of the shape selective catalytic performance of NPs. In addition, the high cost and troublesome availability of these noble metals restricts their applications in larger volume production. A cheap metal like copper can serve as a suitable alternative with its low cost, easy availability, and higher electronic and thermal conductivity, compared to traditional noble metals like silver gold and platinum [30]. Interestingly, some of the properties of special shaped copper nanoparticles are much greater than bulk copper; thus, synthesis of special shaped copper nanoparticles is of interest. However, it is very difficult to fabricate copper nanomaterials in aqueous solution because of its easy oxidizing capability [31]. Until now tremendous efforts are carried out for the preparation of pure metallic nanosized copper. Petit et al. (1993) [32] have used the microemulsion based method to stabilize metallic copper nanoparticles. Cao et al. (2003) [33] synthesized copper nanorods in high yield using a composite template of polyethylene glycol (PEG) and cetyltrimethylammonium bromide (CTAB). Joshi et al. (1998) [6] used oxygen free atmosphere to prevent oxidation of copper nanoparticles in aqueous medium. Similarly, Park et al. (2007) [34] addressed the use of polymer like PVP for the prevention of oxidation and aggregation of copper nanoparticles. However, most of these recent strategies employ oxygen free environments and heavy molecular weight polymers as protecting agents, limiting the usage of copper nanoparticles in aqueous mediums with restrained catalytic efficiency as heavy polymer molecules block large areas of active sites.

Although successful synthesis of copper nanoparticles has been carried out via numerous routes [40], much less is known about the mechanism concerning control of shape and size at the nanoscale level with the basic understanding of shape dependent performance of copper nanostructures as a suitable catalyst. We recently showed the formation of spherical copper nanoparticles in aqueous medium employing SDS surfactant as a protecting agent with its application in reduction of eosin $\mathrm{B}$ dye used as a standard pollutant [41]. The study clearly indicated the application of such nanoparticles in real waste remediation and thus, due to such consideration, extended work was carried out in understanding the formation and wider real application of copper nanostructures as a catalyst for waste water remediation. Thus, the present study is an extended version of our previous report targeted towards the application of copper nanostructures for comparative catalytic reductive degradation of model azo dye methyl orange (MO) to determine the shape influence of copper nanostructures on catalytic, kinetic, and energetic behaviors. The study also compares the basic mechanism that governs the shape of stable copper nanostructures between nanoparticles and nanorods using surfactants like SDS and $\mathrm{CTAB}$ in aqueous solution. In addition, the universal nature of copper nanostructures as catalysts was also highlighted by employing highly efficient copper nanoparticles for reductive degradation of real dyeing waste water samples collected from different regions of Hyderabad city, Pakistan, which, to the best of our knowledge, has not been reported before.

\section{Experimental}

2.1. Materials. All chemicals used were of analytical grade and were used without further purification by employing 
pure Milli-Q water as the preparatory medium. Copper (II) chloride $\left(\mathrm{CuCl}_{2} \cdot 5 \mathrm{H}_{2} \mathrm{O}(97 \%)\right)$, sodium dodecyl sulfate (SDS (98\%)), cetyltrimethylammonium bromide (CTAB (98\%)), vitamin $\mathrm{C}\left(\mathrm{C}_{6} \mathrm{H}_{8} \mathrm{O}_{6}(98 \%)\right)$, and $\mathrm{MO}\left(\mathrm{C}_{1} 4 \mathrm{H}_{14} \mathrm{~N}_{3} \mathrm{NaO}_{3} \mathrm{~S}\right.$ (99\%)) were purchased from $\mathrm{E}$. Merck and sodium borohydride $\left(\mathrm{NaBH}_{4}(98 \%)\right)$, sodium hydroxide $(\mathrm{NaOH}(98 \%))$, and hydrochloric acid ( $\mathrm{HCl}(37 \%))$ were from Sigma-Aldrich.

\subsection{Preparation of Copper Nanostructures. Surfactant capped} copper nanostructures were synthesized via an aqueous reduction route. SDS capped copper nanoparticles ( $\mathrm{Cu}$ NPs) were prepared as mentioned in our previous work [41]. However, slight changes in the optimum amount of precursor ingredients were made to obtain best nanosize particles with maximum catalytic performance. In the typical synthesis of copper nanoparticles, optimized amounts of ingredients were used. $0.5 \mathrm{~mL}$ of $0.02 \mathrm{M}$ copper (II) chloride salt $\left(\mathrm{CuCl}_{2} \cdot 5 \mathrm{H}_{2} \mathrm{O}\right)$ was taken in a test tube. To this was added $10 \mu \mathrm{L}$ of $1.0 \mathrm{M}$ sodium dodecyl sulfate (SDS) followed by the addition of $0.1 \mathrm{~mL}$ of $0.1 \mathrm{M}$ ascorbic acid (vitamin $\mathrm{C}$ ). The mixture volume was adjusted to $9.0 \mathrm{~mL}$ with deionized water and finally $0.3 \mathrm{~mL}$ of $0.01 \mathrm{M}$ sodium borohydride $\left(\mathrm{NaBH}_{4}\right)$ was added slowly. To ensure complete reduction and capping of copper nuclei after reduction, reaction was allowed to proceed for about $15 \mathrm{~min}$. With similar methodology, CTAB capped copper nanorods ( $\mathrm{Cu}$ NRds) were also synthesized by taking $0.1 \mathrm{~mL}$ of $0.03 \mathrm{M}$ copper (II) chloride solution in a similar test tube followed by addition of $30 \mu \mathrm{L}$ of $0.1 \mathrm{M}$ cationic surfactant CTAB. $0.1 \mathrm{~mL}$ of $0.1 \mathrm{M}$ ascorbic acid (vitamin C) was added as a quenching agent and the mixture was diluted with deionized water up to $9.0 \mathrm{~mL}$. Reduction was carried out by the addition of $0.3 \mathrm{~mL}$ of $0.01 \mathrm{M}$ sodium borohydride $\left(\mathrm{NaBH}_{4}\right)$ slowly down the walls of the test tube. This process was repeated several times to obtain stable surfactant capped copper nanostructures, which were further used for characterization and application.

The proposed ionic mechanism for the reduction of $\mathrm{Cu}^{2+}$ to $\mathrm{Cu}^{0}$ with sodium borohydride is given as follows:

$$
\mathrm{Cu}^{2+}+2 \mathrm{BH}_{4}^{-} \longrightarrow \mathrm{Cu}+\mathrm{H}_{2}+\mathrm{B}_{2} \mathrm{H}_{6}
$$

2.3. Characterization. UV-Vis spectroscopy (Lambda 35 of PerkinElmer) was used for tracing SPR of surfactant capped copper nanostructure in the spectral range of $200-800 \mathrm{~nm}$ with the scan rate of $1920 \mathrm{~nm} \mathrm{~s}^{-1}$. Surface interaction study between surfactants and copper nanostructures was carried out with Fourier transform infrared spectroscopy (FTIR) (Nicolet 5700 of Thermo) using the KBr pelleting method, and solid samples were obtained, after parching colloidal dispersions of as-synthesized $\mathrm{Cu}$ nanostructures under nitrogen atmospheres. Morphological characterization with size determination was performed using Atomic force microcopy (AFM) (Agilent 5500) and Scanning Electron Microscopy (SEM) (Jeol, Japan) on freshly cleaved mica and carbon tape surface, respectively. Phase purity and crystalline patterns for $\mathrm{Cu}$ nanostructures were studied using X-ray diffractometry (XRD) (D-8 of Bruker).
2.4. Catalytic Test for Reductive Degradation of Dye. In a representative degradation experiment, $1 \mathrm{mg}$ of SDS capped $\mathrm{Cu}$ NPs or CTAB capped $\mathrm{Cu}$ NRds was deposited on preweighted glass cover slips and dried under nitrogenous atmospheres for complete adhesion to the surface. These cover slips with specific amounts of copper nanostructures were further used in heterogeneous reductive degradation of model azo dye (MO) and real dyeing waste water samples. For an uncatalyzed reaction, an aqueous solution of $100 \mathrm{mM}$ (MO) was taken in a $4 \mathrm{~mL}$ capacity quartz cuvette along with $10 \mathrm{mM}$ of $\left(\mathrm{NaBH}_{4}\right)$ reducing agent. The reaction mixture was studied for some time with an UV-Vis spectrophotometer at room temperature and atmospheric pressure. In a similar manner for catalyzed reaction, glass cover slips with appropriate amounts of surfactant capped $\mathrm{Cu}$ nanostructures were placed inside the sample container, already containing model dye and reductant $\left(\mathrm{NaBH}_{4}\right)$ solution. The catalyzed reaction was followed by measuring the time-dependent fall in absorbance (Abs) at $556 \mathrm{~nm}$. The kinetic study of the reductive degradation procedure was performed at constant temperatures and atmospheric pressure with the calculation of activation energy for nanostructures. Degradation of real dyeing waste water samples was carried out with the most efficient copper nanostructure (SDS capped $\mathrm{Cu}$ NPs). The reductive degradation experiment used the optimum amount of SDS capped $\mathrm{Cu}$ NPs $(0.5 \mathrm{mg})$, previously deposited on a clean glass cover slip. This specific amount was further introduced in a mixture containing $10 \mu \mathrm{L}$ of real waste water sample and $10 \mathrm{mM}$ reductant $\left(\mathrm{NaBH}_{4}\right)$, diluted up to the total volume of $3.5 \mathrm{~mL}$ with deionized water.

\section{Results and Discussion}

3.1. Optical Characterization. Recent advances have allowed metals to be structured on the nanoscale by engineering the surface plasmon modes of metallic nanostructures [42]. Surface plasmons are collective excitations of the electrons at the interface of a metal surface, resulting in absorption of electromagnetic waves [43]. This interesting phenomenon dominates when particle size is brought within the nanoscale regime. In recent years, several studies have shown that optical properties of metal nanoparticles depend on the geometry and size; thus, the optical response of metal nanoparticles (NPs) can be tuned to control shape and size of metal nanostructure $[43,44]$. Since surface plasmon modes of metallic nanoparticles, like $\mathrm{Au}, \mathrm{Ag}$, and $\mathrm{Cu}$, reside within the optical region of the electromagnetic spectrum [42, 45], optical spectroscopy can be used as a primary tool for the investigation of such nanoparticles. UV-Vis spectral profiles for $\mathrm{Cu}$ NPs were recorded with time. The SPR band observed at $569 \mathrm{~nm}$ shows the completely reduced (rich red) colloidal sol as depicted in Figure 1(a).

The absorption spectra have been simulated for spherical copper particles by various earlier reports [30, 46, 47]. As our absorption spectrum is in close resemblance, we conclude that copper nanoparticles were formed in this study. Similarly, the SPR band for Cu NRds (dark reddish brown) was recorded at $545 \mathrm{~nm}$ (Figure 1(b)) with an increase in 


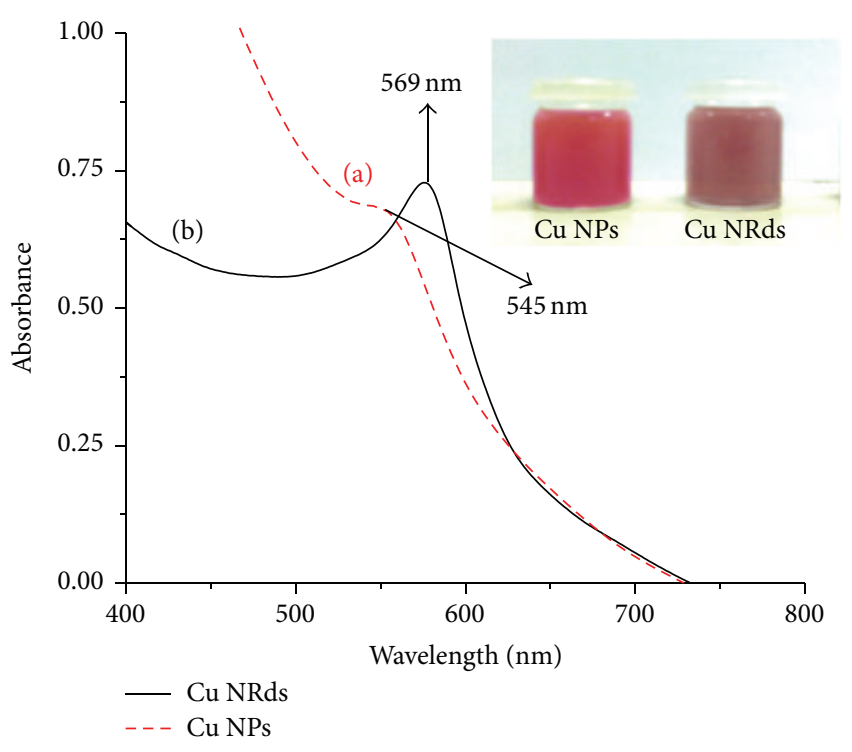

FIgURE 1: SPR bands of (a) SDS capped Cu NPs and (b) CTAB capped Cu NRds.

band width compared to the narrow SPR band of Cu NPs; it is well established that SPR band position and width are highly influenced by particle shape and size [48]. Therefore, the PWHM (peak width half-maximum) was calculated for both as-synthesized copper nanoparticles and nanorods. The PWHM value obtained for $\mathrm{Cu}$ NPs (70) of $100 \mathrm{~nm}$ indicates uniform distribution of particle size. However, for $\mathrm{Cu}$ NRds (118) the value is above $100 \mathrm{~nm}$, which demonstrates large variance in structural size resulting in broad SPR band widths. In this case, increased band width may be the result of considerable interactions between nanoparticles from higher order multipoles and distribution of depolarization as nanoparticles assemble in the form of rod-shaped structures during nucleation. It is interesting to note that the observed color of the $\mathrm{Cu}$ NRds (reddish brown) can also be described as a range/mixture of colors depending on the variance in size of nanorods.

3.2. Fourier Transform Infrared Spectroscopy (FTIR). FTIR spectroscopy can provide vital information concerning surface interactions. The FTIR spectrum of nanoparticles differs considerably from that of the bulk counterpart [49]. In the case of nanoparticles, the surface to volume ratio is very high when compared to bulk form; thus, the number of atoms that constitute the surface can influence the vibration spectra of nanoparticles $[49,50]$. In order to understand the basics of surface interaction/capping between copper nanostructures and surfactants, FTIR spectra were recorder in the range of $4000-400 \mathrm{~cm}^{-1}$. Figure 2 shows FTIR spectra of SDS capped $\mathrm{Cu}$ NPs and CTAB capped $\mathrm{Cu}$ NRds; the FTIR spectra of pure surfactants are also present for comparison. In the case of SDS capped $\mathrm{Cu}$ NPs Figure 2( $\mathrm{c}$ and d), the characteristic vibrational bands of pure SDS can be divided into two regions, concerning its hydrophobic and hydrophilic nature. Twin absorption peaks in the range of $2950-2850 \mathrm{~cm}^{-1}$ are

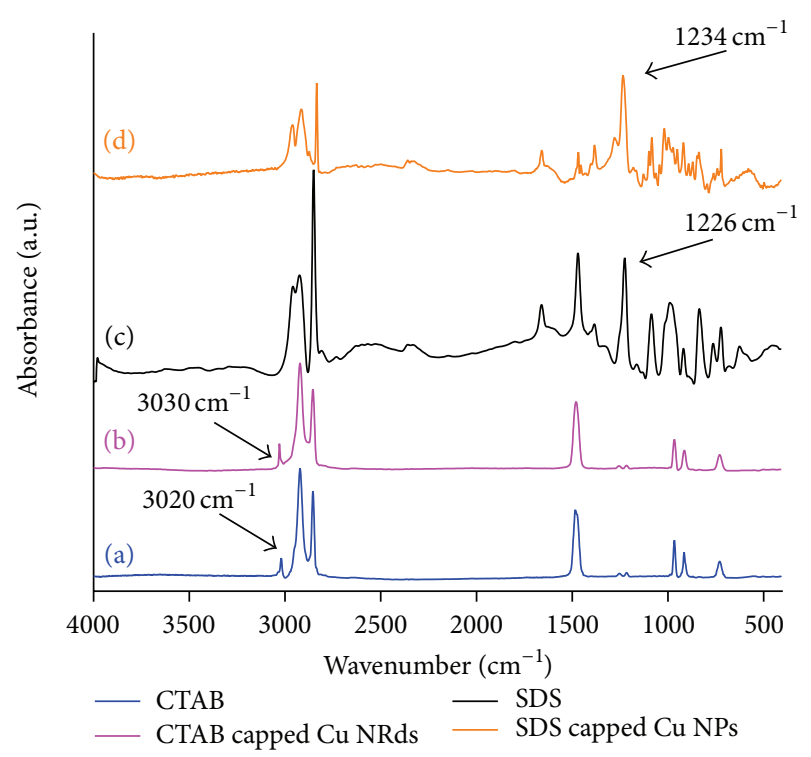

FIGURE 2: FTIR spectra of (a) standard CTAB, (b) CTAB capped $\mathrm{Cu}$ NPs, (c) standard SDS, and (d) SDS capped Cu NRds.

attributed to aliphatic group (tail group) and another band at $1226 \mathrm{~cm}^{-1}$ is attributed to sulfonic acid (head group) of the surfactant [51]. Blue shift in the characteristic absorption band of the sulfonic acid group from $1226 \mathrm{~cm}^{-1}$ in pure SDS to $1234 \mathrm{~cm}^{-1}$ (Figure 2(d)) suggests that the copper nanoparticles were capped by the head group moiety. Furthermore, the absence of the characteristic bands around 623,588 , 534 , and $480 \mathrm{~cm}^{-1}$ excludes the possibility of $\mathrm{Cu}_{2} \mathrm{O}$ and $\mathrm{CuO}$ impurities, respectively $[52,53]$. In the case of $\mathrm{CTAB}$ capped $\mathrm{Cu}$ NRds Figure $2(\mathrm{a}$ and $\mathrm{b}$ ), we understand that intensive vibration bands of CTAB can also be categorized into two different regions, such as the bands associated with methylene tails of surfactant molecules and bands which are associated with alkyl ammonium head groups [54]. A characteristic peak around $3018 \mathrm{~cm}^{-1}$ as shown in Figure 2(a) can be assigned to the symmetric stretching mode of the trimethylammonium head group $\left(\mathrm{CH}_{3}\right)_{3} \mathrm{~N}^{+}$of the surfactant molecules and the most intensive peaks around 2917 and $2847 \mathrm{~cm}^{-1}$ are associated with asymmetric and symmetric stretching vibration modes of the methylene group. A slight shift in the frequency of band associated the head group from $3018 \mathrm{~cm}^{-1}$ to $3025 \mathrm{~cm}^{-1}$ and (Figure 2(b)) suggests that the growth of $\mathrm{Cu}$ NRds is restricted via interaction of the head group $\left[\left(\mathrm{CH}_{3}\right)_{3} \mathrm{~N}^{+}\right]$with the surface of copper. However, the difference in critical micelle concentration (CMC) of the two surfactants and the nature of interaction allowed the directional growth of particles towards self-assembled nanorods in aqueous CTAB medium.

3.3. Atomic Force Microscopy (AFM). Surface morphology plays an important role in the field of catalysis. Atomic force microscopy (AFM) is a powerful technique that can provide direct spatial mapping of surface morphology with nanometer resolution. It requires no specific sample preparation procedures and is easy to interpret and allows for 


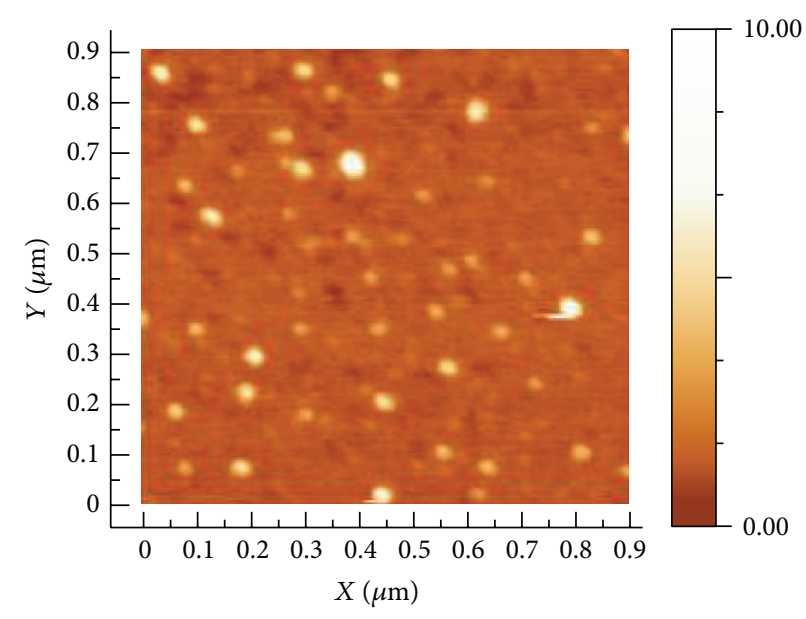

(a)

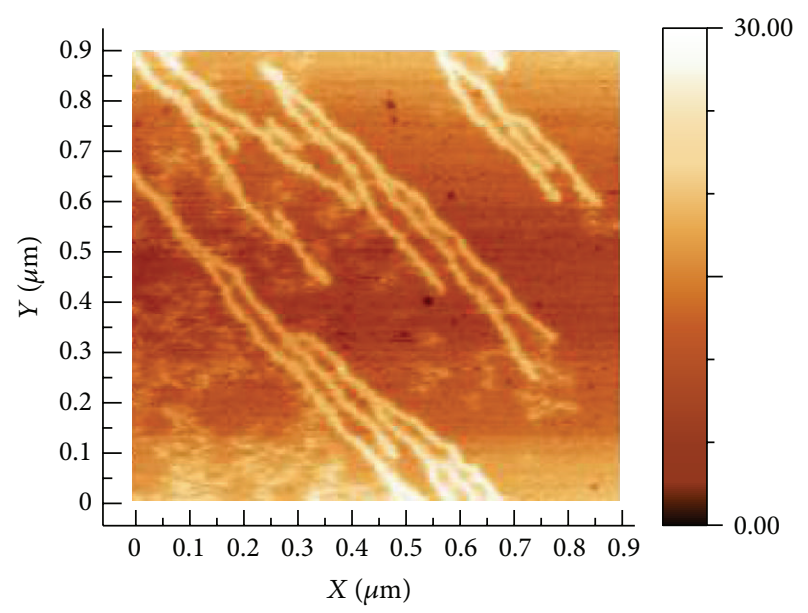

(c)

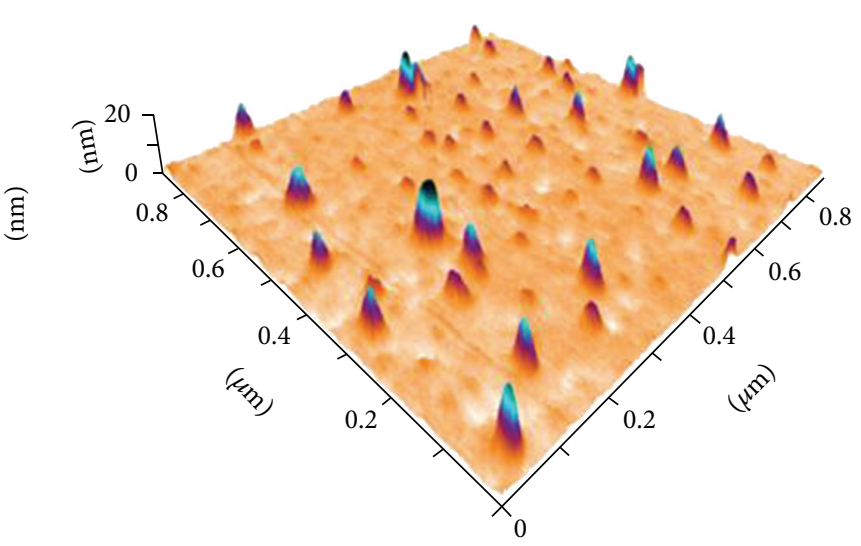

(b)

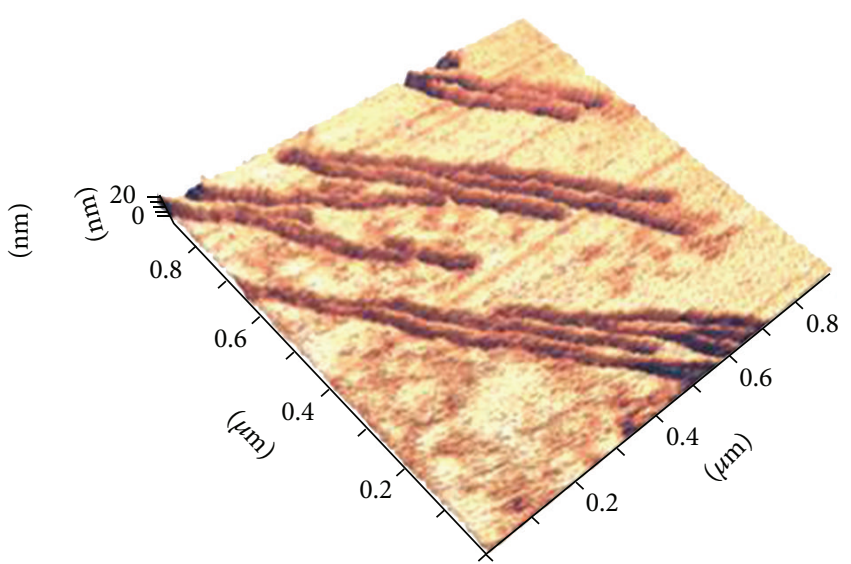

(d)

FIGURE 3: AFM images of Cu nanostructures: (a) typical medium scale AFM image $(0.9 \times 0.9 \mu \mathrm{m})$, (b) topographical map of the SDS capped $\mathrm{Cu}$ NPs, (c) typical medium scale AFM image $(0.9 \times 0.9 \mu \mathrm{m})$, and $(\mathrm{d})$ topographical map of the CTAB capped Cu NRds.

the study of morphological characteristics of samples in a nondistractive way [55]. The tapping modes of AFM imagining were developed especially for studying both SDS capped Cu NPs and CTAB capped Cu NRds. Figure 3(a) shows a typical medium scale AFM image $(0.9 \mu \mathrm{m} \times 0.9 \mu \mathrm{m})$ of the SDS capped $\mathrm{Cu}$ NPs with spherical and uniform shape, whereas a topographical map of nanoparticles is presented in Figure 3(b) where rough surface morphology with dents and irregularities are indicated by highlighted regions. Such rough surfaces have greater number of active sites, which provide greater number of contact points for catalysis [56, 57]. SEM analysis was carried out to get further insight and determine the exact particle size of $\mathrm{Cu}$ NPs. Figure S1(a) in Supplementary Material available online at http://dx.doi.org/10.1155/2015/136164 shows the SEM image with high distribution of as-synthesized $\mathrm{Cu}$ NPs. It can be seen that most nanoparticles are highly dispersed with spherical shape morphology. The average particle diameter calculated from SEM analysis was about $35 \pm 2.8 \mathrm{~nm}$ in the scale range of $15-40 \mathrm{~nm}$. The number of surface atoms per nanoparticle calculated in Table 1 clearly suggests that
$\mathrm{Cu}$ NPs have greater numbers of atoms at the surface as compared to nanorods. In a similar pattern, $\mathrm{Cu}$ NRds were also characterized for morphology. Figure 3(c) shows a medium scale AFM image of CTAB capped Cu NRds where high surface roughness is evident. The SEM image of assynthesized $\mathrm{Cu}$ NRds is presented in Figure S1(b). It can be seen that the formed nanorods are very well dispersed with negligible aggregation. We assume that considerable interaction between small nanodots during nucleation mediated by the surfactant resulted in a self-assembly of particles towards rod-shaped structures. This issue is further discussed later in Section 3.5. The average width of nanorods estimated from SEM analysis was determined to be $65 \pm 3.8 \mathrm{~nm}$ with an average aspect ratio of 9.5. Such a high aspect ratio along with irregular surface topography as depicted in Figure 3(c) allows nanorods to create a network of surfaces in the reaction medium leading to increased physical contacts between catalyst and reactants molecules.

3.4. X-Ray Powder Diffraction (XRD). The X-ray diffractograms of surfactant capped $\mathrm{Cu}$ NPs and NRds are shown 


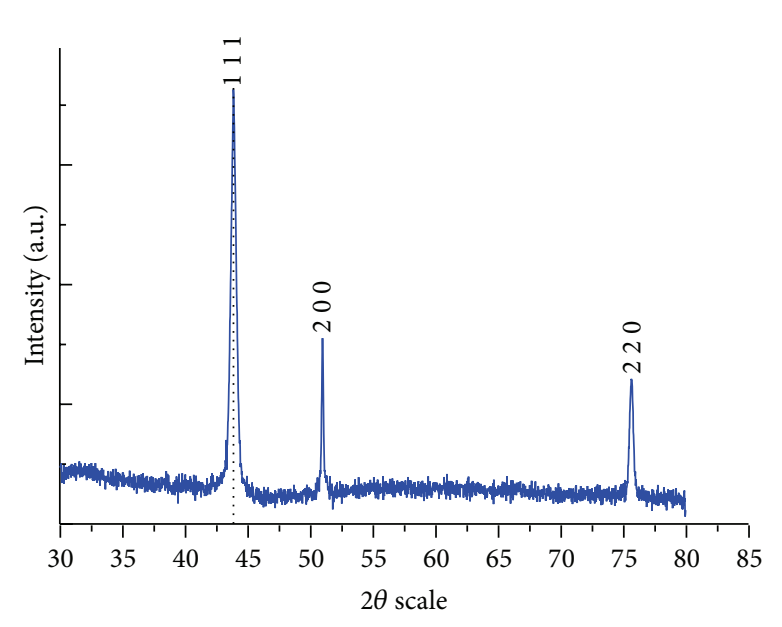

(a)

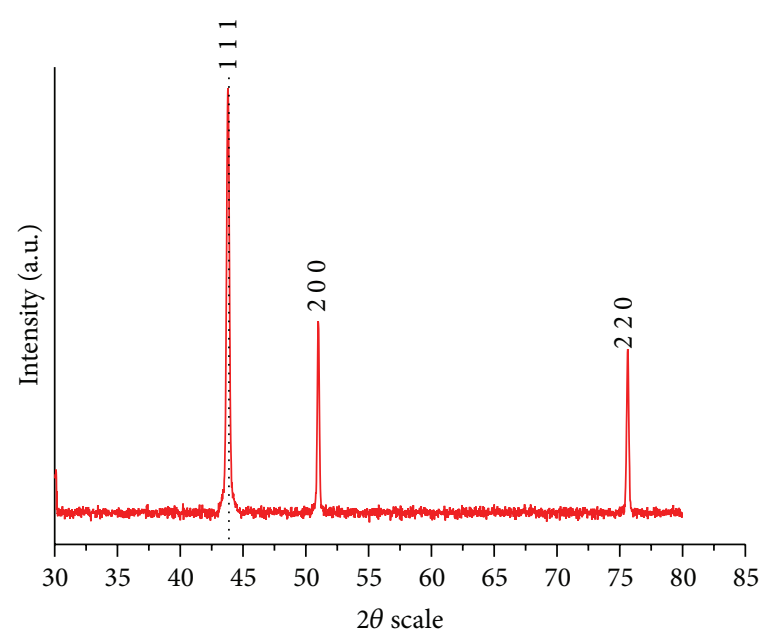

(b)

Figure 4: XRD patterns of (a) Cu NPs and (b) Cu NRds.

in Figures 4(a) and 4(b), respectively. The characteristic Miller indices (1 111$),\left(\begin{array}{lll}2 & 2 & 0\end{array}\right)$, and ( $\left.\begin{array}{lll}2 & 2 & 0\end{array}\right)$ lattice planes were observed for both $\mathrm{Cu}$ NPs and $\mathrm{Cu}$ NRds. The data refer to pure copper metal with face centered cubic structure (FCC). No characteristic peaks indexed to copper oxide were observed, indicating the phase purity of copper metal. The results obtained are in strong corelation with previous reports $[58,59]$. However, differences in intensity and broadness in corresponding peaks were evident. The measured intensity ratio of diffraction peaks indexed as $\left(\begin{array}{lll}1 & 1 & 1\end{array}\right)$ and $\left(\begin{array}{lll}2 & 0 & 0\end{array}\right)$ between $\mathrm{Cu}$ NPs and $\mathrm{Cu}$ NRds was 1.96 and 1.72, respectively. This increased ratio for ( $\left.\begin{array}{lll}1 & 1 & 1\end{array}\right)$ planes refers to the exposed facets along the crystal surface of copper nanoparticles and relatively strong diffraction intensity compared to $\mathrm{Cu}$ NRds. This may be a consequence of an isotropic growth of particular planes during the nucleation step, which has been manifested from their particle and rod-like structural shapes. In addition, increased broadness in XRD peak widths of $\mathrm{Cu}$ NPs relative to $\mathrm{Cu}$ NRds suggests smaller grain size, respectively.

3.5. Growth Mechanism for Copper Nanostructures. Experimental studies were carried out for $[\mathrm{Cu}]$ and $[\mathrm{SDS}]$ at $1: 1$ ratio which resulted in stable blood red colored copper nanoparticles with an SPR band at $569 \mathrm{~nm}$. The mechanism of formation for SDS capped Cu NPs is explained in Figure S2. At concentration of $1 \mathrm{mM}$ which is approximately eight times higher than CMC $\left(8 \times 10^{-3} \mathrm{M}\right)$ of SDS surfactant aqueous medium is rich in SDS micelles; thus, a large population of copper ions are gathered at the negatively charged head group of the surfactant as a result of electrostatic attraction between oppositely charged copper ion and surfactant head group as shown in Figure S2(a). As the electron transfer starts with the abrupt addition of reducing agent $\left(\mathrm{NaBH}_{4}\right)$, explosive nucleation occurs, consuming most of the precursor ions and aggregation of small metal nuclei at the very instant as a consequence of strong interaction between their magnetic dipoles. However, due to the presence of a dense micelle network and strong interaction between oppositely charged groups, most of the nucleation occurs within the SDS micelles which restricts the growth of particles by adsorbing onto the surface. This adsorption of surfactant around nanoparticles results in an overall decrease in grain boundary energy, which is highly related to surface energy. Thus, decreasing the grain boundary energy would result in a decrease in driving force for particle growth (Figure S2(b-d)). AFM and SEM studies indicate the formation of spherical copper nanoparticles at $\left[\mathrm{Cu}^{2+}\right]:[\mathrm{SDS}]$ having $1: 1$ ratio as shown in Figure 3(a). The results are in contrast to those obtained with CTAB at a similar ratio $\left[\mathrm{Cu}^{2+}\right]:[\mathrm{CTAB}]=1: 1$, where copper nanorods are obtained. The formation of copper nanorods can be explained as presented in Figure S3. We know that CTAB is a cationic surfactant; thus, at concentrations above CMC, the precursor ions are mostly located in the micelles head group due to the presence of the counter ion $\mathrm{Br}^{-}$ (Figure S3(a)) not within the micelle network as proposed in Figure S2. With the introduction of reducing agent $\left(\mathrm{NaBH}_{4}\right)$, subsequent unidirectional nucleation occurs as one side of the particles is no longer free due to the presence of micelle (Figure S3(b and c)). This restriction results in unidirectional growth of particle along the specific facets that are exposed to water, ultimately leading to the formation of rod-like structures from the self-assembly of small nanoparticles (Figure S3(d)). The growth mechanism is in correspondence with a recently published report on copper nanorods [45]. Based on an aforementioned mechanism, we conclude that copper nanoparticles and nanorods are both formed by a similar process, that is, surfactant directed growth. However, differences in directional growth of nanostructures arise because of difference in nature, charge, and micelle size. In addition, we also argue that the formation of copper nanostructures is through a template free route with surfactants used as stabilizers and growth directors. It is quite unlikely that rodlike CTAB micelles and SDS associated rod-like structures may form in the absence of additives like sodium salicylate 
and anilinium nitrate as it is evident from the previously published reports $[60,61]$.

3.6. Catalytic Evaluation of Copper Nanostructures for Degradation of MO. The catalytic performance for both SDS capped $\mathrm{Cu}$ NPs and CTAB capped NRds was monitored, taking MO dye as a model compound for organic azo dyes. The progression of the reductive degradation of MO can be easily studied by following the decline in time-dependent absorbance at $550 \mathrm{~nm}$ as shown in Figure 5. The uncatalyzed reaction (Figure 5(a)) was carried out to assess the capability of reductant $\mathrm{NaBH}_{4}(10 \mathrm{mM})$ alone with $\mathrm{MO}(100 \mu \mathrm{M})$, which showed only a small percentage of degradation (up to $8.5 \%$ ) with time. In contrast, catalyzed reaction carried out with surfactant capped copper nanostructures, that is, Cu NPs and $\mathrm{Cu}$ NRds, in a similar sample solution suggested the complete reductive degradation of MO dye (100\%) within 60 and $180 \mathrm{~s}$ of reaction time, respectively (Figures 5(b) and 5(c)). The reaction rate for $\mathrm{MO}$ degradation with copper NPs and $\mathrm{Cu}$ NRds was enhanced 11.2 and 7.5 times, respectively, compared with the results of the control experiment.

The rate of reaction for the heterogeneous catalysis is best described by the Langmuir-Hinshelwood (L-H) model [62], which has the following mathematical formula [18]:

$$
-\frac{d c}{d t}=\frac{k_{L-H} k_{\mathrm{ad}} C}{1+k_{\mathrm{ad}} C},
$$

where $k_{L-H}$ is the reaction rate constant, $k_{\text {ad }}$ is the adsorption coefficient of dye on catalyst, and $C$ is the variable concentration at any time $t$. For pseudo first-order reaction, the value of $k$ ad $C$ is very small as compared to 1 in the denominator of (2). So, by integrating (2) for simplification, we obtain

$$
\ln \left(\frac{C_{0}}{C}\right)=k_{L-H} k_{\mathrm{ad}} t=-k t .
$$

Here, $C_{0}$ is the initial concentration and $k=k_{L-H} k_{\mathrm{ad}}$ is the pseudo first-order reaction rate constant.

Figure 6 shows the plot with linear relationship of natural logarithm of ratio of initial concentration of $\mathrm{MO}$ and relative remaining concentration after reductive degradation versus the corresponding reaction time (s). Linear regression analysis was used to evaluate the reaction rate constants for the reductive degradation of MO by surfactant capped copper nanostructures. Rate constant $k$ was found to be $0.056 \pm$ 0.001 and $0.036 \pm 0.0015 \mathrm{~s}^{-1}$ for the corresponding catalytic reductive degradation of $\mathrm{MO}$ by $\mathrm{Cu}$ NPs and $\mathrm{Cu}$ NRds, respectively. The $R^{2}$ values clearly suggest that the removal of MO seems to fit pseudo first-order kinetics.

Differences in catalytic performance between SDS capped $\mathrm{Cu}$ NPs and CTAB capped Cu NRds can also be explained based on the difference in the nanostructure-support contact area that is dependent on the particles shape and size. It is known that many catalytic processes occur at the perimeter interface around the nanoparticles where the fraction of step sites increases significantly with decreasing particle size [63]. Here, $\mathrm{Cu}$ NPs were found to have degraded MO 1.5 times faster than $\mathrm{Cu}$ NRds; thus, such enhancement in reaction rate is a function of two major factors: number of surface atoms per nanoparticle and activation energy.

Comparatively, the larger numbers of surface atoms of $\mathrm{Cu}$ NPs (323025) than of Cu NRds (121457) would provide greater numbers of low coordination sites (sharp corners and edges) over the surface of the nanocatalyst. In contrast, for $\mathrm{Cu}$ NRds, it can be understood that particles at connecting interfaces of rods are much less exposed to the surface resulting in decreased numbers of low coordinated sites compared to the independent spherical $\mathrm{Cu}$ nanoparticles, which have all sites exposed as surface and available for coordination. Also, the larger size of $\mathrm{Cu}$ NRds provides low surface coverage per unit volume in the reaction mixture, whereas for $\mathrm{Cu}$ NPs their smaller size and homogenous distribution provides increased numbers of contact sites for the reactant molecules per unit volume within the reaction medium.

The shape effect of copper nanostructures on the activation energy of reductive degradation of $\mathrm{MO}$ with $\mathrm{NaBH}_{4}$ was evaluated via catalytic experiment conducted as a function of three different temperatures $\left(35^{\circ} \mathrm{C}, 45^{\circ} \mathrm{C}\right.$, and $\left.50^{\circ} \mathrm{C}\right)$ for both SDS capped $\mathrm{Cu}$ NPs and CTAB capped $\mathrm{Cu}$ NRds. For each experiment, absorption spectra in the range of 400 to $700 \mathrm{~nm}$ were recorded at different time intervals. The effective rate constant values for both $\mathrm{Cu}$ NPs and $\mathrm{Cu}$ NRds were evaluated as a function of temperature as follows: Cu NPs: $0.14 \pm 0.02$, $0.25 \pm 0.01$, and $0.28 \pm 0.05 \mathrm{~s}^{-1}$ and Cu NRds: $0.10 \pm 0.01$, $0.21 \pm 0.02$, and $0.27 \pm 0.01 \mathrm{~s}^{-1}$ at $30^{\circ} \mathrm{C}, 40^{\circ} \mathrm{C}$, and $55^{\circ} \mathrm{C}$, respectively. The obtained values were used in the following linear form of the Arrhenius equation to estimate apparent activation energy:

$$
\ln k=-\frac{E_{a}}{R} \times \frac{1}{T}+\ln A,
$$

where $E_{a}$ is activation energy, $T$ is the absolute temperature, and $R$ is the universal gas constant. A linear plot of $\ln k$ versus $1 / T$ was obtained for degradation carried out with SDS capped $\mathrm{Cu}$ NPs and CTAB capped NRds and the value of the apparent activation energy was estimated from the linear regression as shown in Figure 7. The activation energy obtained for the reaction carried out with $\mathrm{Cu}$ NPs $(21+$ $\left.1.0 \mathrm{~kJ} \mathrm{~mol}^{-1}\right)$ is much smaller compared to $E_{a}$ value obtained for the reaction carried out with $\mathrm{Cu}$ NRds $\left(33+1.2 \mathrm{~kJ} \mathrm{~mol}^{-1}\right)$. The significantly lower apparent activation energies obtained with SDS capped $\mathrm{Cu}$ NPs then a CTAB capped NRds may be attributed to the rough surface morphology of spherical copper nanoparticles that offer higher numbers of low coordination sites from all three dimensions belonging to the nanosize regime. Many studies have shown that the ratio of corner and edge atoms increases with the decrease of crystal size [64-66]. At the nanoscale, edge and corner atoms exhibit open coordination sites that may result in significantly different bond enthalpies and desorption energies compared to macrostructures. In contrast, $\mathrm{Cu}$ NRds have large sizes and lower surface coordination sites as indicated from their smaller number of surface atoms per nanoparticle. Thus, variation in surface morphology, when shape of particles changes from spherical to rod, is responsible for changes in activation energy of the overall system. Some literature data on decolorization of MO dye by different methods, 


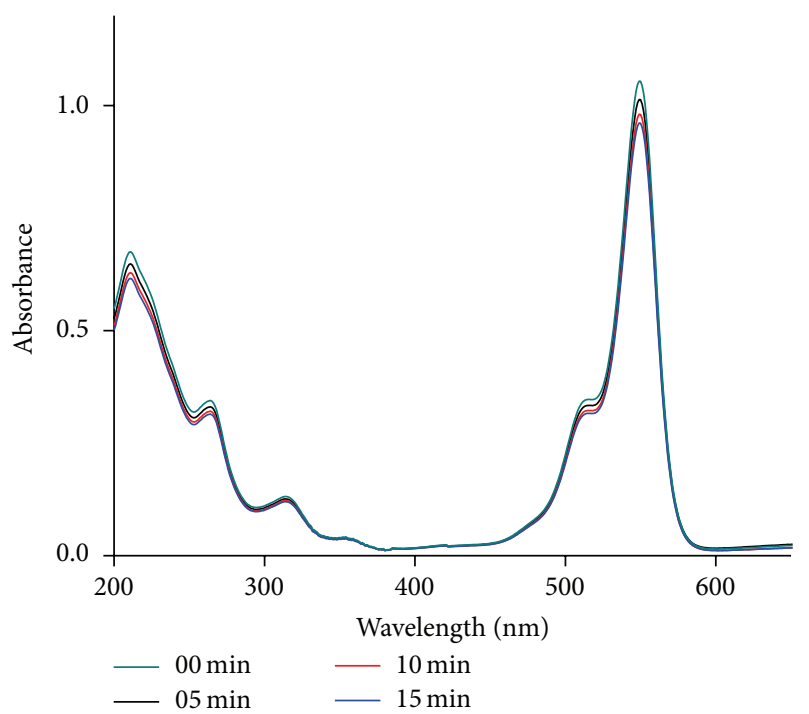

(a)

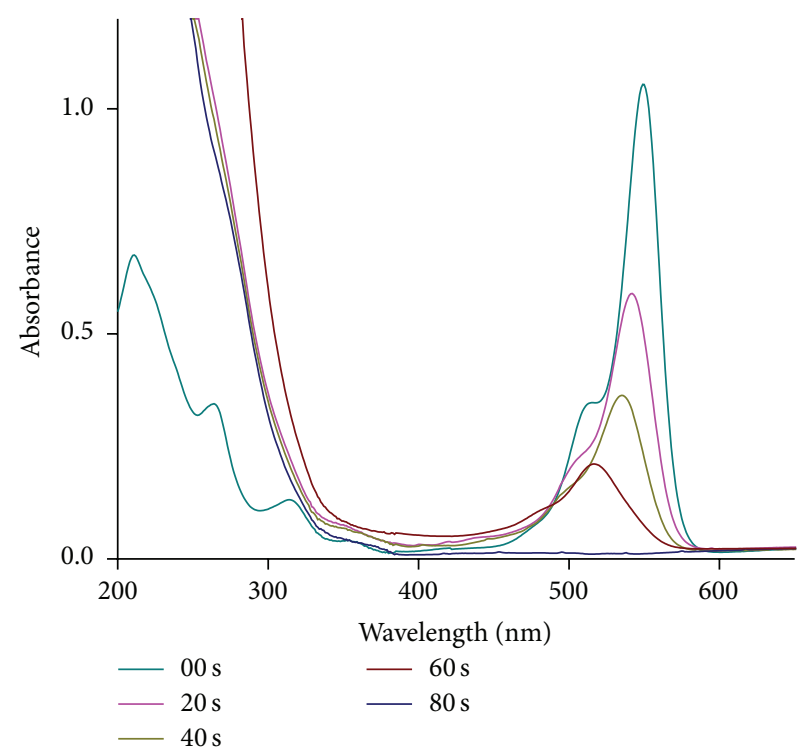

(b)

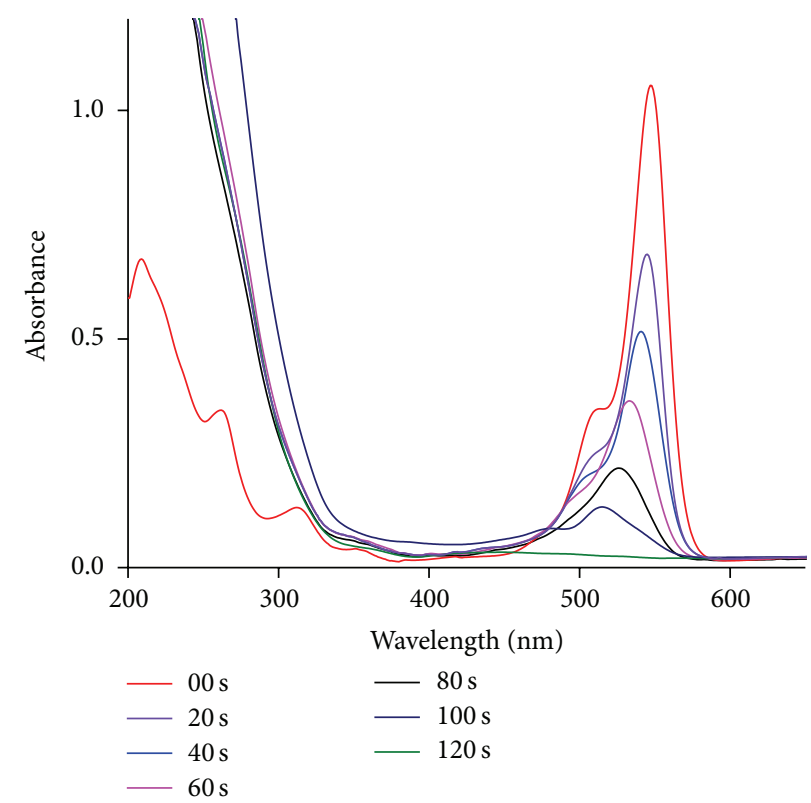

(c)

FIGURE 5: UV-Vis spectral profiles for (a) uncatalyzed reduction of $100 \mu \mathrm{M}(\mathrm{MO})$ with $500 \mu \mathrm{L} 0.01 \mathrm{M}\left(\mathrm{NaBH}_{4}\right)$ and (b) and (c) catalyzed reductive degradation of MO in a similar sample environment with SDS capped Cu NPs and CTAB capped Cu NRds, respectively.

comparative with that obtained in this paper, are summarized in Table 1.

Table 1 shows that all the parameters tested for the catalytic system used in this paper are more effective than those of the previously reported methods. Small amounts of catalyst (1 mg surfactant capped Cu nanostructures), $100 \mathrm{mM}$ reductant $\mathrm{NaBH}_{4}$, low activation energy $\left(E_{a}=21 \pm 1.0\right.$ and $33 \pm 1.2 \mathrm{~kJ} \mathrm{~mol}^{-1}$ ), with advanced reductive degradation achieved in just 80 and $120 \mathrm{~s}$ for $\mathrm{Cu}$ NPs and $\mathrm{Cu}$ NRds, respectively, at room temperature and pressure provide a clear edge over reports listed in the literature.
3.7. Reductive Degradation of Real Dyeing Waste Water Samples. The universality of surfactant capped copper nanostructures as a heterogeneous catalyst for dye degradation was examined by degrading real waste water dye containing samples. However, the degradation was carried out only with SDS capped Cu NPs because of their higher efficiency compared to CTAB capped $\mathrm{Cu}$ NRds. Real waste water samples were collected from drains of three different local textile industries of Hyderabad region. Catalytic degradation was performed with a similar methodology as mentioned above, with optimized weight of $\mathrm{Cu}$ NPs $(0.5 \mathrm{mg})$ and $0.5 \mathrm{~mL}$ 
TABLE 1: Comparative results obtained for MO degradation and decolorization by various methods.

\begin{tabular}{|c|c|c|c|}
\hline Degrading system & Reaction conditions & Observations & References \\
\hline $\begin{array}{l}\text { Gold silver nanocore/silica } \\
\text { nanoshell (photocatalytic } \\
\text { system) }\end{array}$ & $\begin{array}{l}{[\text { catalyst }]=500 \mathrm{mg} \mathrm{L}^{-1}} \\
{[\mathrm{MO}]=50 \mathrm{ppm}} \\
\text { Size }\left(\mathrm{SiO}_{2}=30 \mathrm{~nm}\right) \\
(\text { Core shell } \mathrm{Ag} \mathrm{NPs}=20 \mathrm{~nm}) \\
(\text { Core shell Au NPs }=15 \mathrm{~nm})\end{array}$ & $\begin{array}{l}K=0.01 \pm 0.001,0.023 \pm 0.0002,0.035 \\
\pm 0.0005 \mathrm{~min}^{-1} \text { for } \mathrm{SiO}_{2}, \\
\text { Au NPs and } \mathrm{Ag} \mathrm{NPs}, \text { respectively } \\
100 \% \text { degradation after } 120,70 \text {, and } \\
65 \text { min for } \mathrm{SiO}_{2}, \mathrm{Au} \mathrm{NPs} \text {, and Ag NPs, } \\
\text { respectively }\end{array}$ & {$[35]$} \\
\hline $\begin{array}{l}\text { Nanosized } \mathrm{ZnO} \\
\text { (photocatalyst) }\end{array}$ & $\begin{array}{l}{[\mathrm{ZnO}]=2.5 \mathrm{~g} \mathrm{~L}^{-1} \text { (calcined at }} \\
\left.550^{\circ} \mathrm{C} \text { for } 120 \mathrm{~min}\right) \\
{[\mathrm{MO}]=5 \text { to } 50 \mathrm{mg} \mathrm{L}^{-1}} \\
\text { Average size }=20 \mathrm{~nm}\end{array}$ & $\begin{array}{l}K=0.0631 \pm 0.00035 \mathrm{~min}^{-1} \\
100 \% \text { degradation after } 120 \mathrm{~min}\end{array}$ & {$[36]$} \\
\hline $\begin{array}{l}\text { GT-Fe NPs } \\
\text { (fenton-like catalyst) }\end{array}$ & $\begin{array}{l}{[\mathrm{GT}-\mathrm{Fe} \mathrm{NPs}]=50.0 \mathrm{mg}} \\
{\left[\mathrm{H}_{2} \mathrm{O}_{2}\right]=5.0 \mathrm{~mL} \text { of } 10.0 \%} \\
{[\mathrm{MO}]=50.0 \mathrm{mg} \mathrm{L}^{-1}} \\
\text { Size } 40-60 \mathrm{~nm} \text { range }\end{array}$ & $\begin{array}{l}K=0.019 \pm 0.0002 \mathrm{~min}^{-1} \\
100 \% \text { degradation after } 360 \mathrm{~min}\end{array}$ & [37] \\
\hline $\begin{array}{l}\text { Nanoscale zerovalent Iron } \\
\text { Particles (NZVI) }\end{array}$ & $\begin{array}{l}{[\mathrm{NZVI}]=3 \mathrm{~g} \mathrm{~L}^{-1}} \\
{[\mathrm{MO}]=11.4 \mathrm{mg} \mathrm{L}^{-1}} \\
\text { Size } 50-100 \mathrm{~nm}\end{array}$ & $\begin{array}{l}K=0.34 \pm 0.004 \mathrm{~min}^{-1} \\
E_{A}=23 \pm 1.5 \mathrm{~kJ} \mathrm{~mol}^{-1} \\
100 \% \text { degradation after } 24 \mathrm{~min}\end{array}$ & [38] \\
\hline $\begin{array}{l}\text { Electrochemical-assisted } \\
\text { photodegradation on } \mathrm{TiO}_{2} \\
\text { thin films }\end{array}$ & $\begin{array}{l}{\left[\mathrm{TiO}_{2}\right]=2.0 \mathrm{mg}} \\
{[\mathrm{MO}]=10 \mathrm{ppm}}\end{array}$ & $\begin{array}{l}K=0.219 \pm 0.00025 \mathrm{~min}^{-1} \\
E_{A}=18.63 \pm 3.5 \mathrm{~kJ} \mathrm{~mol}^{-1} \\
100 \% \text { degradation after } 120 \mathrm{~min}\end{array}$ & {$[39]$} \\
\hline In this study & $\begin{array}{l}{[\mathrm{Cu} \mathrm{NPs}],[\mathrm{Cu} \text { NRds }]=0.1 \mathrm{mg}} \\
{[\mathrm{MO}]=100 \mathrm{uM}} \\
{\left[\mathrm{NaBH}_{4}\right]=10 \mathrm{mM}} \\
\text { Size: } \mathrm{Cu} \text { NPs }=(\text { average width }=20 \mathrm{~nm} \\
\text { and average height }=3.7 \mathrm{~nm}) \\
\mathrm{Cu} \text { NRds }=(\text { average width }=48 \mathrm{~nm} \text { and } \\
\text { average height }=14 \mathrm{~nm})\end{array}$ & $\begin{array}{l}{[\mathrm{Cu} \mathrm{NPs}]=K=0.032 \pm 0.001 \mathrm{~s}^{-1}} \\
E_{A}=21 \pm 1.0 \mathrm{~kJ} \mathrm{~mol}^{-1} 100 \% \\
\text { degradation after } 80 \mathrm{sec} \\
{[\mathrm{Cu} \text { NRds }]=K=0.056 \pm 0.0015 \mathrm{~s}^{-1}} \\
E_{A}=33 \pm 1.2 \mathrm{~kJ} \mathrm{~mol}^{-1} \\
100 \% \text { degradation after } 120 \mathrm{~s}\end{array}$ & \\
\hline
\end{tabular}

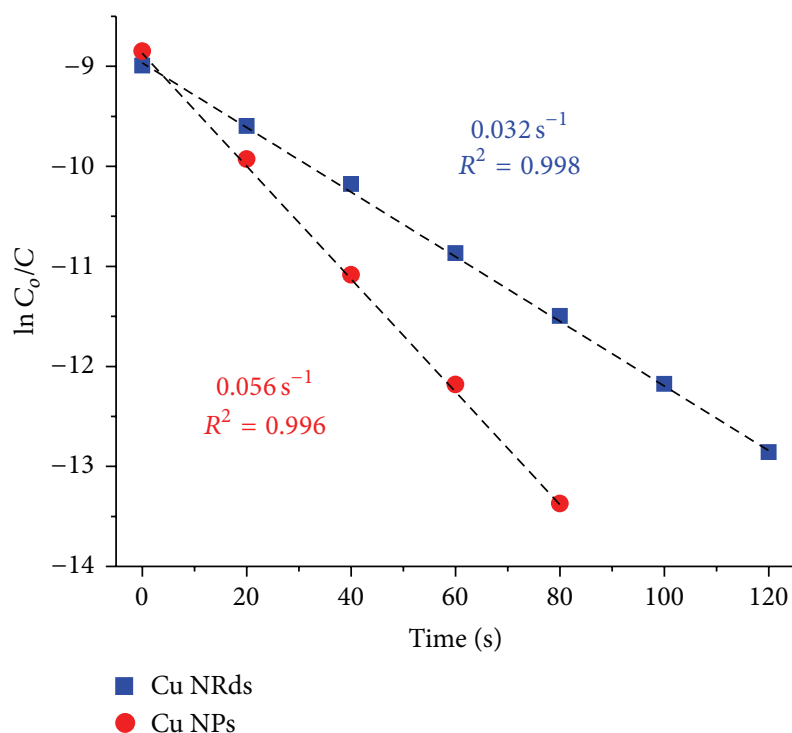

FIGURE 6: Linear regression plot showing pseudo first-order kinetics for the $\mathrm{Cu}$ nanostructure catalyzed reductive degradation of $\mathrm{MO}$ with SDS capped Cu NPs and CTAB capped NRds.

of $100 \mathrm{mM}\left(\mathrm{NaBH}_{4}\right)$ reductant and $10 \mu \mathrm{L}$ of real sample diluted up to $0.3 \mathrm{~mL}$ with deionized water was used for the study of real environmental samples. Figure S4 shows UVVis spectra for the reductive degradation of real samples.

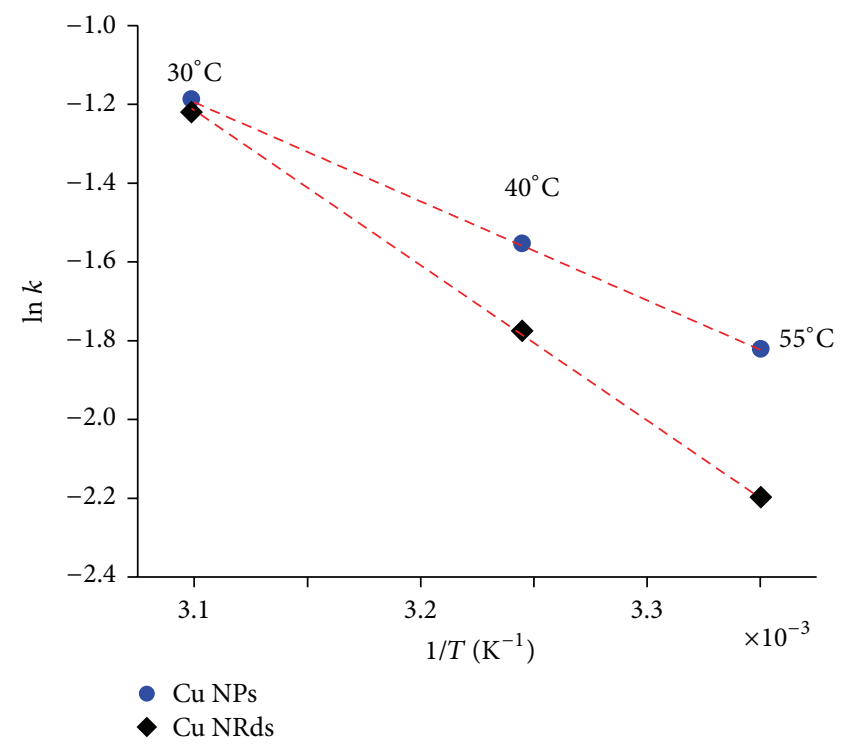

FIGURE 7: Linear regression for Arrhenius equation with estimation of corresponding activation energy for surfactant capped Cu NPs and NRds.

Complete degradation was observed in very short reaction time for each sample irrespective of their chemical nature and color intensities, indicating the high efficiency and comprehensive nature of $\mathrm{Cu}$ NPs as a catalyst. Figure S4(a, 
b, and c) represents the spectra for an uncatalyzed control test with very small decrease in the absorbance with reaction time. In contrast, catalyzed tests in Figure S4(d, e, and f) show excellent reductive degradation (100\%) with time. Small differences between the reaction rates can be explained on the basis of structural difference and concentration of various dye molecules present in each real sample.

\section{Conclusions}

From the above experimental results, we conclude that surfactant capped $\mathrm{Cu}$ nanoparticles and nanorods can be efficiently synthesized in an aqueous medium via a surfactant assisted wet-chemical reduction route. The study is unique, as we have shown the formation of copper nanostructures with directional growth using long alkyl chain containing salts compared to the conventional common seed-mediated strategy. Another aspect of this study highlights the basic mechanism for shape variation of the copper nanostructures in aqueous surfactant medium and depicts the formation to be based on concentration [surfactant] to [copper ion] ratio, nature of surfactant, micelle size, and alignments of the initially formed particles. Shape and size dependent catalytic activity of copper nanostructures is also evaluated by degrading methyl orange in the presence of $\mathrm{NaBH}_{4}$ used as a reductant under ambient reaction conditions. Comparison has been made to show their different catalytic performance in terms of kinetic and thermodynamic parameters. Copper nanoparticles were found to be a highly efficient catalyst, as compared to copper nanorods, because of their smaller work functions and high number of surface atoms. Lastly, the universal nature of copper nanostructures as a catalyst was demonstrated by efficiently degrading real dyeing waste water samples with copper nanoparticles, collected from drainage of local industries, situated in Hyderabad region, Pakistan. The study could be extended to all types of reductive degradation of other dyes as well as other pollutants in waste water research.

\section{Conflict of Interests}

The authors declare that there is no conflict of interests regarding the publication of this paper.

\section{Acknowledgments}

The authors acknowledge the Higher Education Commission, Islamabad, Pakistan, and the National Centre of Excellence in Analytical Chemistry, University of Sindh, Jamshoro, Pakistan, for provision of financial assistance and facilities during this research. The authors, equally, highly thank and cordially appreciate the financial support by King Saud University for provision of funding via their Research Project no. RGP-VPP-236.

\section{References}

[1] K. Mallick, M. J. Witcomb, and M. S. Scurrell, "Preparation and characterization of a conjugated polymer and copper nanoparticle composite material: a chemical synthesis route," Materials Science and Engineering B: Solid-State Materials for Advanced Technology, vol. 123, no. 2, pp. 181-186, 2005.

[2] R. Das, S. S. Nath, and R. Bhattacharjee, "Luminescence of copper nanoparticles," Journal of Luminescence, vol. 131, no. 12, pp. 2703-2706, 2011.

[3] M. Abdulla-Al-Mamun, Y. Kusumoto, and M. Muruganandham, "Simple new synthesis of copper nanoparticles in water/acetonitrile mixed solvent and their characterization," Materials Letters, vol. 63, no. 23, pp. 2007-2009, 2009.

[4] C. J. Murphy and N. R. Jana, "Controlling the aspect ratio of inorganic nanorods and nanowires," Advanced Materials, vol. 14 , no. 1, pp. 80-82, 2002.

[5] A. Henglein, "Small-particle research: physicochemical properties of extremely small colloidal metal and semiconductor particles," Chemical Reviews, vol. 89, no. 8, pp. 1861-1873, 1989.

[6] S. S. Joshi, S. F. Patil, V. Iyer, and S. Mahumuni, "Radiation induced synthesis and characterization of copper nanoparticles," Nanostructured Materials, vol. 10, no. 7, pp.1135-1144, 1998.

[7] J. N. Solanki, R. Sengupta, and Z. V. P. Murthy, "Synthesis of copper sulphide and copper nanoparticles with microemulsion method," Solid State Sciences, vol. 12, no. 9, pp. 1560-1566, 2010.

[8] Y. H. Kim, Y. S. Kang, W. J. Lee, B. G. Jo, and J. H. Jeong, "Synthesis of $\mathrm{Cu}$ nanoparticles prepared by using thermal decomposition of $\mathrm{Cu}$-oleate complex," Molecular Crystals and Liquid Crystals, vol. 445, pp. 231-238, 2006.

[9] Z. Yan, R. Bao, C. Z. Dinu, Y. Huang, A. N. Caruso, and D. B. Chrisey, "Laser ablation induced agglomeration of $\mathrm{Cu}$ nanoparticles in sodium dodecyl sulfate aqueous solution," Journal of Optoelectronics and Advanced Materials, vol. 12, no. 3, pp. 437-439, 2010.

[10] Q.-M. Liu, T. Yasunami, K. Kuruda, and M. Okido, "Preparation of $\mathrm{Cu}$ nanoparticles with ascorbic acid by aqueous solution reduction method," Transactions of Nonferrous Metals Society of China, vol. 22, no. 9, pp. 2198-2203, 2012.

[11] Q.-M. Liu, R.-L. Yu, G.-Z. Qiu, Z. Fang, A.-L. Chen, and Z.W. Zhao, "Optimization of separation processing of copper and iron of dump bioleaching solution by Lix $984 \mathrm{~N}$ in Dexing Copper Mine," Transactions of Nonferrous Metals Society of China, vol. 18, no. 5, pp. 1258-1261, 2008.

[12] H.-T. Zhu, C.-Y. Zhang, and Y.-S. Yin, "Rapid synthesis of copper nanoparticles by sodium hypophosphite reduction in ethylene glycol under microwave irradiation," Journal of Crystal Growth, vol. 270, no. 3-4, pp. 722-728, 2004.

[13] O. Coussy and T. Fen-Chong, "Crystallization, pore relaxation and micro-cryosuction in cohesive porous materials," Comptes Rendus-Mecanique, vol. 333, no. 6, pp. 507-512, 2005.

[14] A. A. Athawale, P. P. Katre, M. Kumar, and M. B. Majumdar, "Synthesis of CTAB-IPA reduced copper nanoparticles," Materials Chemistry and Physics, vol. 91, no. 2-3, pp. 507-512, 2005.

[15] K.-S. Wang, C.-L. Lin, M.-C. Wei et al., "Effects of dissolved oxygen on dye removal by zero-valent iron," Journal of Hazardous Materials, vol. 182, no. 1-3, pp. 886-895, 2010.

[16] Y. He, J.-F. Gao, F.-Q. Feng, C. Liu, Y.-Z. Peng, and S.-Y. Wang, "The comparative study on the rapid decolorization of azo, anthraquinone and triphenylmethane dyes by zero-valent iron," Chemical Engineering Journal, vol. 179, pp. 8-18, 2012. 
[17] M. A. Rauf, M. A. Meetani, and S. Hisaindee, "An overview on the photocatalytic degradation of azo dyes in the presence of $\mathrm{TiO}_{2}$ doped with selective transition metals," Desalination, vol. 276, no. 1-3, pp. 13-27, 2011.

[18] Z. Sun, Y. Chen, Q. Ke, Y. Yang, and J. Yuan, "Photocatalytic degradation of cationic azo dye by $\mathrm{TiO}_{2}$ /bentonite nanocomposite," Journal of Photochemistry and Photobiology A: Chemistry, vol. 149, no. 1-3, pp. 169-174, 2002.

[19] X. Lu, B. Zhang, Y. Wang et al., "Nano-Ag-loaded hydroxyapatite coatings on titanium surfaces by electrochemical deposition," Journal of the Royal Society Interface, 2011.

[20] A. D. Bokare, R. C. Chikate, C. V. Rode, and K. M. Paknikar, "Iron-nickel bimetallic nanoparticles for reductive degradation of azo dye Orange $\mathrm{G}$ in aqueous solution," Applied Catalysis B: Environmental, vol. 79, no. 3, pp. 270-278, 2008.

[21] I. Poulios, E. Micropoulou, R. Panou, and E. Kostopoulou, "Photooxidation of eosin Y in the presence of semiconducting oxides," Applied Catalysis B: Environmental, vol. 41, no. 4, pp. 345-355, 2003.

[22] L. Ma, X. Wang, B. Wang et al., "Photooxidative degradation mechanism of model compounds of poly ( $p$-phenylenevinylenes) [PPVs]," Chemical Physics, vol. 285, pp. 85-94, 2002.

[23] Y. Xiong and H. T. Karlsson, "Approach to a two-step process of dye wastewater containing acid red B," Journal of Environmental Science and Health-Part A Toxic/Hazardous Substances and Environmental Engineering, vol. 36, no. 3, pp. 321-331, 2001.

[24] E. L. Appleton, "A nickel-iron wall against contaminated groundwater," Environmental Science and Technology, vol. 30, no. 12, pp. 536A-539A, 1996.

[25] S. S. Hassan, A. R. Solangi, M. H. Agheem, Y. Junejo, N. H. Kalwar, and Z. A. Tagar, "Ultra-fast catalytic reduction of dyes by ionic liquid recoverable and reusable mefenamic acid derived gold nanoparticles," Journal of Hazardous Materials, vol. 190, no. 1-3, pp. 1030-1036, 2011.

[26] L. Xu, X.-C. Wu, and J.-J. Zhu, "Green preparation and catalytic application of Pd nanoparticles," Nanotechnology, vol. 19, no. 30, Article ID 305603, 2008.

[27] A. Nafady, H. I. Afridi, S. Sara, A. Shah, and A. Niaz, "Direct synthesis and stabilization of Bi-sized cysteine-derived gold nanoparticles: reduction catalyst for methylene blue," Journal of the Iranian Chemical Society, vol. 8, no. 1, pp. S34-S43, 2011.

[28] L. Ai and J. Jiang, "Catalytic reduction of 4-nitrophenol by silver nanoparticles stabilized on environmentally benign macroscopic biopolymer hydrogel," Bioresource Technology, vol. 132, pp. 374-377, 2013.

[29] T. K. Sau, A. Pal, and T. Pal, "Size regime dependent catalysis by gold nanoparticles for the reduction of eosin," Journal of Physical Chemistry B, vol. 105, no. 38, pp. 9266-9272, 2001.

[30] T. M. D. Dang, T. T. T. Le, E. Fribourg-Blanc, and M. C. Dang, "Synthesis and optical properties of copper nanoparticles prepared by a chemical reduction method," Advances in Natural Sciences: Nanoscience and Nanotechnology, vol. 2, no. 1, Article ID 015009, 2011.

[31] T. M. D. Dang, T. T. T. Le, E. Fribourg-Blanc, and M. C. Dang, "The influence of solvents and surfactants on the preparation of copper nanoparticles by a chemicalreduction method," Advances in Natural Sciences: Nanoscience and Nanotechnology, vol. 2, no. 2, Article ID 025004, 2011.

[32] C. Petit, P. Lixon, and M.-P. Pileni, "In situ synthesis of silver nanocluster in AOT reverse micelles," Journal of Physical Chemistry, vol. 97, no. 49, pp. 12974-12983, 1993.
[33] X. Cao, F. Yu, L. Li, Z. Yao, and Y. Xie, "Copper nanorod junctions templated by a novel polymer-surfactant aggregate," Journal of Crystal Growth, vol. 254, no. 1-2, pp. 164-168, 2003.

[34] B. K. Park, S. Jeong, D. Kim, J. Moon, S. Lim, and J. S. Kim, "Synthesis and size control of monodisperse copper nanoparticles by polyol method," Journal of Colloid and Interface Science, vol. 311, no. 2, pp. 417-424, 2007.

[35] Y. Badr and M. A. Mahmoud, "Photocatalytic degradation of methyl orange by gold silver nano-core/silica nano-shell," Journal of Physics and Chemistry of Solids, vol. 68, no. 3, pp. 413419, 2007.

[36] C. Chen, J. Liu, P. Liu, and B. Yu, "Investigation of photocatalytic degradation of methyl orange by using nano-sized $\mathrm{ZnO}$ catalysts," Advances in Chemical Engineering and Science, vol. 1, no. 1, pp. 9-14, 2011.

[37] T. Shahwan, S. Abu Sirriah, M. Nairat et al., "Green synthesis of iron nanoparticles and their application as a Fenton-like catalyst for the degradation of aqueous cationic and anionic dyes," Chemical Engineering Journal, vol. 172, no. 1, pp. 258-266, 2011.

[38] Y. He, J. F. Gao, F. Q. Feng, C. Liu, Y. Z. Peng, and S. Y. Wang, "The comparative study on the rapid decolorization of azo, anthraquinone and triphenylmethane dyes by zero-valent iron," Chemical Engineering Journal, vol. 179, pp. 8-18, 2012.

[39] Z. Zainal, C. Y. Lee, M. Z. Hussein, A. Kassim, and N. A. Yusof, "Electrochemical-assisted photodegradation of dye on $\mathrm{TiO}_{2}$ thin films: investigation on the effect of operational parameters," Journal of Hazardous Materials, vol. 118, no. 1-3, pp. 197-203, 2005.

[40] A. Umer, S. Naveed, N. Ramzan, and M. S. Rafique, "Selection of a suitable method for the synthesis of copper nanoparticles," Nano, vol. 7, no. 5, Article ID 1230005, 2012.

[41] R. A. Soomro, S. T. H. Sherazi, Sirajuddin et al., "Synthesis of air stable copper nanoparticles and their use in catalysis," Advanced Materials Letters, vol. 5, no. 4, pp. 191-198, 2014.

[42] F. Chen, N. Alemu, and R. L. Johnston, "Collective plasmon modes in a compositionally asymmetric nanoparticle dimer," AIP Advances, vol. 1, no. 3, Article ID 032134, 2011.

[43] T. Ghodselahi, M. A. Vesaghi, and A. Shafiekhani, "Study of surface plasmon resonance of $\mathrm{Cu} @ \mathrm{Cu}_{2} \mathrm{O}$ core-shell nanoparticles by Mie theory," Journal of Physics D: Applied Physics, vol. 42, no. 1, Article ID 015308, 2009.

[44] C. Noguez, "Surface plasmons on metal nanoparticles: the influence of shape and physical environment," Journal of Physical Chemistry C, vol. 111, no. 10, pp. 3606-3619, 2007.

[45] S. K. Ghosh and T. Pal, "Interparticle coupling effect on the surface plasmon resonance of gold nanoparticles: from theory to applications," Chemical Reviews, vol. 107, no. 11, pp. 47974862, 2007.

[46] S. De and S. Mandal, "Surfactant-assisted shape control of copper nanostructures," Colloids and Surfaces A: Physicochemical and Engineering Aspects, vol. 421, pp. 72-83, 2013.

[47] M. Vaseem, K. M. Lee, D. Y. Kim, and Y.-B. Hahn, "Parametric study of cost-effective synthesis of crystalline copper nanoparticles and their crystallographic characterization," Materials Chemistry and Physics, vol. 125, no. 3, pp. 334-341, 2011.

[48] V. Sharma, K. Park, and M. Srinivasarao, "Colloidal dispersion of gold nanorods: historical background, optical properties, seed-mediated synthesis, shape separation and self-assembly," Materials Science and Engineering R: Reports, vol. 65, no. 1-3, pp. 1-38, 2009. 
[49] J. A. Eastman, L. J. Thompson, and B. J. Kestel, "Narrowing of the palladium-hydrogen miscibility gap in nanocrystalline palladium," Physical Review B, vol. 48, no. 1, pp. 84-92, 1993.

[50] T. R. Yang, H. E. Horng, H. C. Yang, L. J. Jang, W. N. Kang, and S. S. Yom, "Infrared properties of single crystal $\mathrm{MgAl}_{2} \mathrm{O}_{4}$, a substrate for high-temperature superconducting films," Physica C: Superconductivity, vol. 235-240, no. 2, pp. 1445-1446, 1994.

[51] S. R. Taffarel and J. Rubio, "Adsorption of sodium dodecyl benzene sulfonate from aqueous solution using a modified natural zeolite with CTAB," Minerals Engineering, vol. 23, no. 10, pp. 771-779, 2010.

[52] M. S. Usman, N. A. Ibrahim, K. Shameli, N. Zainuddin, and W. M. Z. W. Yunus, "Copper nanoparticles mediated by chitosan: synthesis and characterization via chemical methods," Molecules, vol. 17, no. 12, pp. 14928-14936, 2012.

[53] K. Tian, C. Liu, H. Yang, and X. Ren, "In situ synthesis of copper nanoparticles/polystyrene composite," Colloids and Surfaces A: Physicochemical and Engineering Aspects, vol. 397, pp. 12-15, 2012.

[54] Z. M. Sui, X. Chen, L. Y. Wang et al., "Capping effect of CTAB on positively charged Ag nanoparticles," Physica E: Low-Dimensional Systems and Nanostructures, vol. 33, no. 2, pp. 308-314, 2006.

[55] X. Gu, T. Nguyen, M. Oudina et al., "Microstructure and morphology of amine-cured epoxy coatings before and after outdoor exposures-an AFM study," Journal of Coatings Technology Research, vol. 2, no. 7, pp. 547-556, 2005.

[56] A. Chaudhari, C.-C. S. Yan, and S.-L. Lee, "Autopoisoning reactions over rough surface: a multifractal scaling analysis," International Journal of Chemical Kinetics, vol. 37, no. 3, pp. 175182, 2005.

[57] S.-L. Lee and C.-K. Lee, "Heterogeneous reactions over fractal surfaces: a multifractal scaling analysis," International Journal of Quantum Chemistry, vol. 64, no. 3, pp. 337-350, 1997.

[58] P. Chokratanasombat and E. Nisaratanaporn, "Preparation of ultrafine copper powders with controllable size via polyol process with sodium hydroxide addition," Engineering Journal, vol. 16, no. 4, pp. 39-46, 2012.

[59] M. Kooti and L. Matouri, "Fabrication of nanosized cuprous oxide using fehling's solution," Scientia Iranica, vol. 17, no. 1, pp. 73-78, 2010.

[60] M. A. Watzky and R. G. Finke, "Transition metal nanocluster formation kinetic and mechanistic studies. A new mechanism when hydrogen is the reductant: slow, continuous nucleation and fast autocatalytic surface growth," Journal of the American Chemical Society, vol. 119, no. 43, pp. 10382-10400, 1997.

[61] J. Hu, T. W. Odom, and C. M. Lieber, "Chemistry and physics in one dimension: synthesis and properties of nanowires and nanotubes," Accounts of Chemical Research, vol. 32, no. 5, pp. 435-445, 1999.

[62] A. Houas, H. Lachheb, M. Ksibi, E. Elaloui, C. Guillard, and J.-M. Herrmann, "Photocatalytic degradation pathway of methylene blue in water," Applied Catalysis B: Environmental, vol. 31, no. 2, pp. 145-157, 2001.

[63] K. M. Bratlie, H. Lee, K. Komvopoulos, P. Yang, and G. A. Somorjai, "Platinum nanoparticle shape effects on benzene hydrogenation selectivity," Nano Letters, vol. 7, no. 10, pp. 30973101, 2007.

[64] R. B. Greegor and F. W. Lytle, "Morphology of supported metal clusters: determination by EXAFS and chemisorption," Journal of Catalysis, vol. 63, no. 2, pp. 476-486, 1980.
[65] S. Ladas, "The effect of metal particle size on the stoichiometry of adsorption," Surface Science, vol. 175, no. 1, pp. L681-L686, 1986.

[66] R. van Hardeveld and F. Hartog, "The statistics of surface atoms and surface sites on metal crystals," Surface Science, vol. 15, no. 2, pp. 189-230, 1969. 

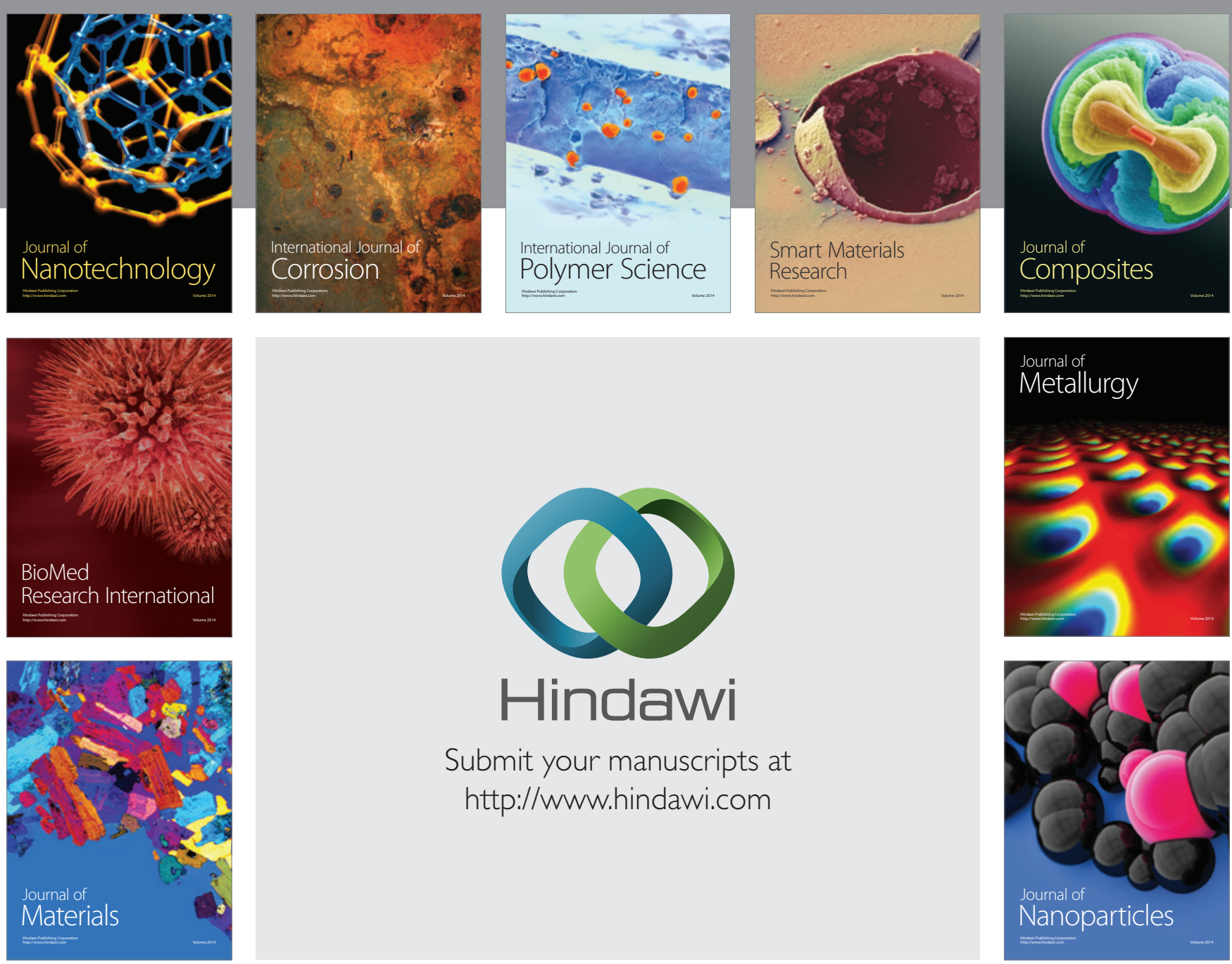

Submit your manuscripts at http://www.hindawi.com
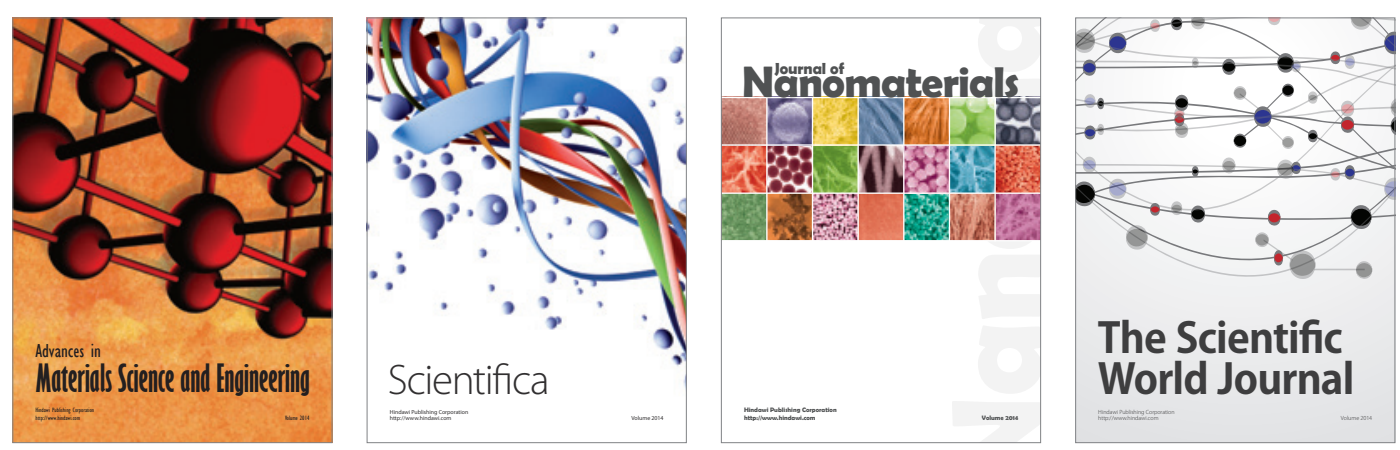

\section{The Scientific World Journal}
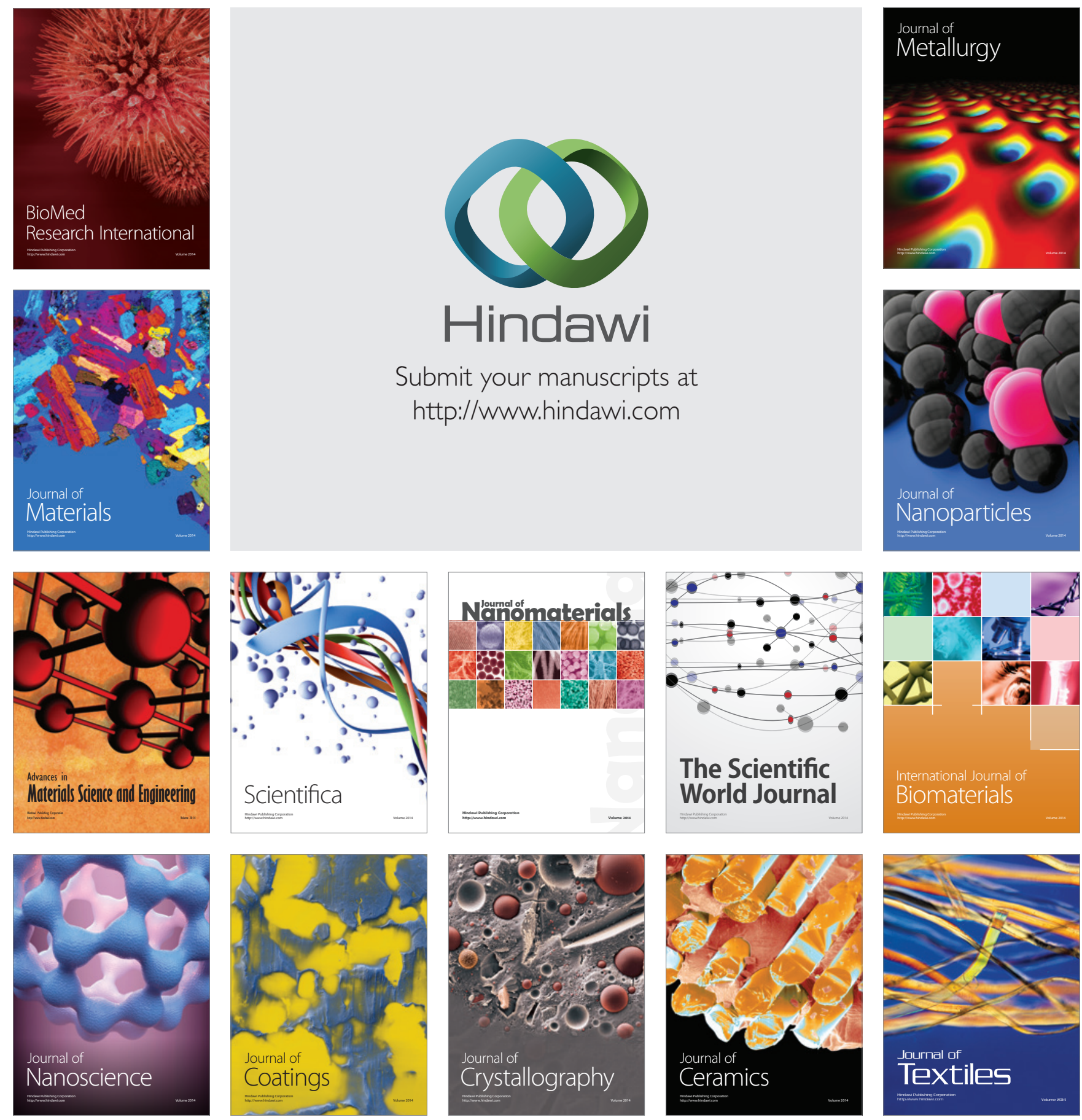